\title{
Studies of Synthetic Macrocyclic Complexes of Co (II) and Mn( II) in the Catalytic Oxidation of Hydroquinones
}

\author{
P. Tevatia*, Sweety, Anuj, Randhir Singh \\ Department of Chemistry, Gurukula Kangri Vishwavidyalaya, Haridwar(UK), India
}

\begin{abstract}
Four new hexamethyl tetraaza macrocyclic complexes of Co(II) and Mn(II) were synthesized by template method. These were characterized by elemental analysis, cyclic voltammetry, UV and IR spectroscopic methods. All of these were used for the catalytic oxidation of hydroquinones. The oxidation reactions were carried out in the presence as well as in the absence of axial bases. The results were also compared with the blank experiments. Co(II)-A macrocyclic complex was found to be the most efficient catalyst for the oxidation reaction. The catalytic efficiency, however, also depends on the substituents in substrate hydroquinone.
\end{abstract}

Keywords: Tetraaza macrocyclic complexes, catalysis.

\section{Introduction}

A large amount of interest in the field of macrocyclic chemistry of cobalt, copper and nickel has arisen during past decades due to their multiferous role in chemistry and industry. The study of the macrocyclic complexes has also been received much attention for synthetic catalysts which increased the oxidizing ability of $\mathrm{H}_{2} \mathrm{O}_{2}$. The use of $\mathrm{H}_{2} \mathrm{O}_{2}$ along with the synthetic macrocycles (termed as activators) have been developed and are being used as catalyst/ activators. These have the potential to replace the chlorine containing complexes that are currently in use for paper delignification and bleaching processes. The $\mathrm{H}_{2} \mathrm{O}_{2}$ bleaching produces only environmentally benign byproduct such as $\mathrm{H}_{2} \mathrm{O}$ and $\mathrm{O}_{2}$, thus eliminating the chlorinated organic byproducts which are associated with chlorine delignification and bleaching processes. The macrocyclic activators have made the use of $\mathrm{H}_{2} \mathrm{O}_{2}$ as a bleaching agent more efficient as the macrocyclic complexes catalyse the reaction to promote the dissociation of $\mathrm{H}_{2} \mathrm{O}_{2}$ into hydroxyl radicals which are involved in the oxidation or bleaching of the remaining lignin, thus making $\mathrm{H}_{2} \mathrm{O}_{2}$ a more powerfull oxidizing agent. The macrocyclic activators allows $\mathrm{H}_{2} \mathrm{O}_{2}$ to break down more lignin in a shorter span of time of 1 hour in comparison to 6 hours as wells as these retain high selectivity towards oxidizing lignin over cellulose. Additionally in the presence of macrocyclic complexes for bleaching process by $\mathrm{H}_{2} \mathrm{O}_{2}$ lower reaction temperatures can be used as $50^{\circ} \mathrm{C}$ instead of $120^{\circ} \mathrm{C}$.[1-2]

The present communication comprises the synthesis and catalytic oxidation of hydroquinones in the presence of synthesized macrocyclic complexes of $\mathrm{Co}(\mathrm{II})$ and $\mathrm{Mn}$ (II). This autooxidation produces $\mathrm{H}_{2} \mathrm{O}_{2}$ alongwith benzoquinones. The axial ligation costants and thermodynamic parameters for these types of macrocyclic complexes have already been reported.[3-6] The catalytic oxidation of methyl hydroquinone by tetramethyl tetraaza cobalt macrocyclic complexes has also been reported.[7-12] We carried out the autooxidation of methoxy and some other hydroquinones in presence of $\mathrm{Co}(\mathrm{II})$ and $\mathrm{Mn}(\mathrm{II})$ complexes of hexamethyl tetraaza macrocyclic ligands $\mathbf{A}$ and $\mathbf{B}$.

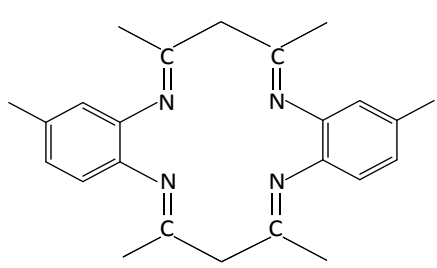

A

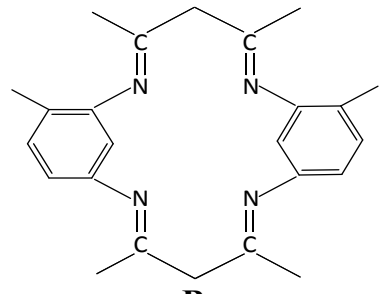

B

The oxidation was carried out in the atmosphere of air in $\mathrm{CHCl}_{3}$ solvent. It has also been observed with substituted macrocyclic complexes of Co (II) that substituent groups affect the rate of oxidation of Hydroquinones. Accordingly, the results of an investigation of catalytic oxidation of some substrates using Co (II) macrocyclic complex (A) have been taken into account for these studies.

\section{Experimental}

FT-IR spectra were recorded with Schimadzu- 8400 S double beam spectrophotometer by KBr DRS method. Methyl substituted $\mathrm{Me}_{6}$ dibenzo [1,4,8,11] tetraazacyclotetradecaene- $\mathrm{N}_{4}$ complexes of $\mathrm{Co}$ (II) and $\mathrm{Mn}$ (II) respectively were prepared by template method. All the reactants were of AR grade purchased from 
TCI, India. The autooxidation studies of hydroquinones by using macrocyclic complexes of Co(II) and $\mathrm{Mn}$ (II) were carried out in the absence and in presence of axial base.

\subsection{Preparation of Macrocyclic Complexes}

6,13-Dihydro $\mathrm{Me}_{6}$ dibenzo [b,i] [1,4,8,11]-tetraazacyclotetradecaene cobalt(II) chloride [Co(II)-A]

2 moles of 3,4-diamino toluene $(0.488 \mathrm{~g}), 2$ moles of acetyl acetone $(0.400 \mathrm{~g})$ and 1 mole of cobalt(II) chloride hexahydrate $(0.476 \mathrm{~g})$ were dissolved in $50-60 \mathrm{ml}$ methanol and the reaction mixture was refluxed for about 6-8 hours. A change in color appeared; the solution was concentrated in rotary evaporator and dried in vacuum. Violet colored crystals of macrocyclic complex $\mathrm{Co}(\mathrm{II})$-A obtained and characterized by various techniques like UV-VIS, IR and cyclic voltammetry etc. $[13,14]$

7,15-Dihydro $\mathrm{Me}_{6}$ dibenzo $[b, j][1,5,9,13]$-tetraazacyclohexadecaene cobalt(II) chloride [Co(II)-B]

2 moles of 2,4-diamino toluene $(0.488 \mathrm{~g}), 2$ moles of acetyl acetone $(0.400 \mathrm{~g})$ and 1 mole of cobalt(II) chloride hexahydrate $(0.476 \mathrm{~g})$ were dissolved in $50-60 \mathrm{ml}$ methanol and the reaction mixture was refluxed for about 6-8 hours. A change in color appeared; the solution was concentrated in rotary evaporator and dried in vacuum. Brown colored crystals of macrocyclic complex $\mathrm{Co}(\mathrm{II})-\mathrm{B}$ obtained and characterized by various techniques like UV-VIS, IR and cyclic voltammetry etc.[15-17]

Macrocyclic complex Mn(II)-A and macrocyclic complex Mn(II)-B were also prepared by the same procedure using $\mathrm{Mn}(\mathrm{II})$ chloride. $[18,19]$

\subsection{Catalytic Oxidation of Hydroquinones}

The substrate hydroquinone $(3 \mathrm{mmol})$ was dissolved in chloroform $(250 \mathrm{ml})$ and the complex $(0.25$ mmol) was added to this solution. Air was bubbled into the resulting mixture for 4 hrs with constant stirring at $30^{\circ} \mathrm{C}$. The resulting reaction mixture was filtered and the filtrate was concentrated on a rotary evaporator. The concentrate was applied on the top of a chromatographic silica gel (60-120 mesh) column and eluted with dichloromethane. The elute was evaporated to dryness on rotary evaporator and the solid material was recrystallized with petroleum ether to obtain the pure 1,4-benzoquinone yellow niddles. The various benzoquinone products were charecterised by melting points and IR data (Table 1).

\section{Result and Discussion}

In the presence of air, the macrocyclic complexes of Co (II) and Mn (II) with ligands A and B were used for the catalysis of hydroquinone. The hydroquinone was added in a 12-fold over the catalyst. The oxidation reaction is shown in scheme-1.The results (\% yield) are given in table 2.

These studies clearly show that Co (II)-A macrocyclic complex is the best suited as catalyst for this auto-oxidation. The catalytic activity of Co (II)-A is evident as blank experiment (with no catalyst) does not give oxidation product at all. However, manganese complexes are not efficient as catalyst as apparent in table 2 .

Further, the catalytic activity of macrocyclic complex Co (II)-A seems to be dependent on substrate. The oxidation results of various hydroquinone in presence of Co (II)-A have been shown in table 1 . Hydroquinone gives 44\% 1,4-benzoquinone, while the yield of oxidation products of chloro, methoxy and 2,3,5trimethyl hydroquinones are $50 \%, 74 \%$ and $70 \%$ respectively. It is apparent from these results that the oxidation reaction is influenced by the electronic and/or steric effects exerted by the substituent groups in benzene ring. $[24,25]$

It has been observed that the catalytic activity of macrocyclic complex Co (II)-A depends upon the properties of the added axial base. The yield of the oxidation product was low on addition of pyridine and 3,4diamino pyridine as an axial base as these coordinates with Co to reduce its catalytic efficiency (Table 3 ). The catalytic oxidation may involve dehydrogenation for a variety of hydroquinones, the dehydrogenation of hydroquinone may be considered by stepwise $\mathrm{H}$-atom transfer to $\mathrm{O}$ atom in the formation of 1,4-benzoquinones and $\mathrm{H}_{2} \mathrm{O}_{2}$, however, no definite evidence for this mechanism can be given at this time.[26,27]

\section{Figures and Tables}

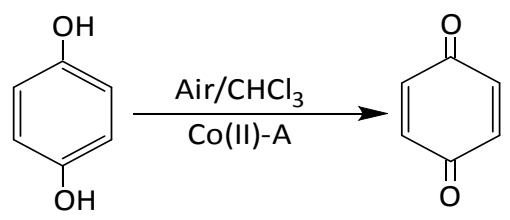
Scheme-1<smiles>COC1=CC(=O)C=CC1=O</smiles> 
Studies of Synthetic Macrocyclic Complexes of Co (II) and Mn( II) in the Catalytic Oxidation of

Table 1

\begin{tabular}{|c|c|c|c|c|c|}
\hline \multirow{2}{*}{$\begin{array}{c}\text { Substituent } \\
\text { Group(R) }\end{array}$} & \multirow{2}{*}{$\begin{array}{l}\text { Yield }(\%) \text { of } 1,4- \\
\text { benzoquinones }\end{array}$} & \multirow{2}{*}{$\begin{array}{c}\text { IR } \\
v(C=O) \mathrm{cm}^{-1}\end{array}$} & \multicolumn{2}{|c|}{ Melting point $\left({ }^{\circ} \mathrm{C}\right)$} & \multirow[t]{2}{*}{ Reference } \\
\hline & & & This study & literature & \\
\hline$-\mathrm{H}$ & 44 & 1662 & 110 & 113 & [20] \\
\hline $2,3,5-\left(\mathrm{CH}_{3}\right)_{3}$ & 70 & 1639 & 30 & 31 & [21] \\
\hline$-\mathrm{Cl}$ & 50 & 1655 & 58 & 57 & [22] \\
\hline$-\mathrm{OCH}_{3}$ & 74 & 1634,1672 & 145 & 147 & [23] \\
\hline
\end{tabular}

Table 2

\begin{tabular}{|c|c|c|}
\hline Catalyst & Used gas & $\begin{array}{c}\text { Yield } \\
\text { \% of 1,4-benzoquinone }\end{array}$ \\
\hline Co (II)-A & air & 44 \\
\hline Co (II)-B & air & 20 \\
\hline Mn (II)-A & air & 15 \\
\hline Mn (II)-B & air & 00 \\
\hline No catalyst added & air & 00 \\
\hline
\end{tabular}

Table 3

\begin{tabular}{|c|c|c|}
\hline $\begin{array}{c}\text { Catalyst Co(II)-A } \\
(\mathbf{m . m o l})\end{array}$ & $\begin{array}{c}\text { Base } \\
(\mathbf{m} . \mathbf{m o l})\end{array}$ & $\begin{array}{c}\text { Yield } \\
\text { \% of 1,4-benzoquinones }\end{array}$ \\
\hline 0.25 & 3,4-Diamino pyridine(3.0) & 15 \\
\hline 0.25 & Pyridine(0.6) & 35 \\
\hline 0.25 & Pyridine(6.0) & 28 \\
\hline 0.25 & No base & 44 \\
\hline
\end{tabular}

\section{Conclusion}

Hexamethyl tetraaza macrocyclic complexes of $\mathrm{Co}(\mathrm{II})$ and $\mathrm{Mn}$ (II) were synthesized and used for the catalysis of the oxidation of hydroquinones. It has been observed that hexamethyl tetraaza macrocyclic complex of cobalt, $\mathrm{Co}$ (II)-A, is an efficient catalyst for the oxidation of hydroquinones into corresponding benzoquinones alongwith the production of $\mathrm{H}_{2} \mathrm{O}_{2}$. The catalytic efficiency seems to be enhanced by the presence of electron releasing groups in aromatic ring.

\section{References}

[1]. J. A. Miller, L. Alexander, D. I. Mori, A. D. Ryabov and T. J. Collins, New J. Chem., 37, 3488, 2013.

[2]. C. P. Horwitz, D. R. Fooksman, L. D. Vuocolo, S. W. Gordon-Wylie, N. J. Cox and T. J. Collins, J. Am. Chem. Soc., 120, 4867, 1998.

[3]. K. Sakata, M. Hashimoto and H. Yoshino, Inorg. Chim. Acta, 99, 231, 1985

[4]. A. Pezeshk, F. T. Greenaway and G. Vincow, Inorg. Chem., 17, 3421, 1978.

[5]. L. H. Vogt, Jr., J. G. Wirth and H. L. Finkbeiner, J. Org. Chem., 34, 273, 1969.

[6]. D. L. Tomaja, L. H. Vogt, Jr. and J. G. Wirth, J. Org. Chem., 35, 2029, 1970.

[7]. K. Sakata, T. Kikutake, Y. Shigaki, M. Hashimoto, Y. Kato and H. Ogawa, Inorg. Chim. Acta, 144, 1, 1988.

[8]. P. Hudec, J. Catal., 53, 228, 1978.

[9]. A. Nishinaga and T. Matsuura, J. Chem. Soc., Chem. Commun., 9, 1973.

[10]. A. Nishinaga, K. Nishizawa, H. Tomita and T. Matsuura, J. Am. Chem. Soc., 99, 1287, 1977.

[11]. A. Nishinaga, T. Shimizu and T. Matsuura, Tetrahedron Lett., 3748, 1978.

[12]. D. R. Turner, B. Smith, E. C. Spencer, A. E. Goeta, I. R. Evans, D. A. Tocher, J. A. K. Howard and J. W. Steed, New J. Chem., 29, 90, 2005.

[13]. R. A. Sheikh, Sheikh Shreaz, L. A. Khan and A. A. Hashmi, J. Chem. Pharm. Res., 2(3), $274,2010$.

[14]. S. N. Dmitrieva, N. I. Sidorenko, N. A. Kurchavov, A. I. Vedernikov, A. Y. Freidzon, L. G. Kuzmina, A. K. Buryak, T. M. Buslaeva, A. A. Bagaturyants, Y. A. Strelenko, J. A. K. Howard and S. P. Gromov, Inorg. Chem., 50, 7500, 2011.

[15]. A. K. Yadava, H. S. Yadav and D. P. Rao, Eur. Chem. Bull., 2(5), 255, 2013.

[16]. S. Senthamil Selvi, A. Dayalan, Int. J. Chem. Tech. Research, 5, 6, 2890, 2013.

[17]. C. S. Dilip, V. Sivakumar and J. J. Prince, Ind. J. Chem. Tech., 19, 351, 2012.

[18]. N.B. Prakash, Scholar. J. Phys. and App. Chemistry, 1(1), 1, 2013.

[19]. R. E. Andrew and A. B. Chaplin, Dalton Trans., 43, 1413, 2014.

[20]. H. W. Underwood Jr. and W. L. Walsh, Org. Synth., II, 553, 1943.

[21]. E. Noelting and T. Bauman, Ber. Dtsch. Chem. Ges., 18, 1150, 1885.

[22]. H. Van Erp, Ber. Dtsch. Chem. Ges., 58, 663, 1925.

[23]. C. Balraj, A. Satheshkumar, K. Ganesh and K. P. Elango, RSC Adv., 2, 12384, 2012.

[24]. L. P. Harding, J. C. Jeffery, T. Riis-Johannessen, C. R. Rice and Z. T. Zeng, Dalton Trans., $2396,2004$.

[25]. A. Channaa and J. W. Steed, Dalton Trans, 2455, 2005.

[26]. K. Sakata, M. Hashimoto, N. Tagami and Y. Murakami, Bull. Chem. Soc. Jpn., 53, 2262, 1980.

[27]. A. Nishinaga, T. Matsuura and T. Tozo, J. Chem. Soc., Chem. Commun., 896, 1974. 